NAOSITE: Nagasaki University's Academic Output SITE

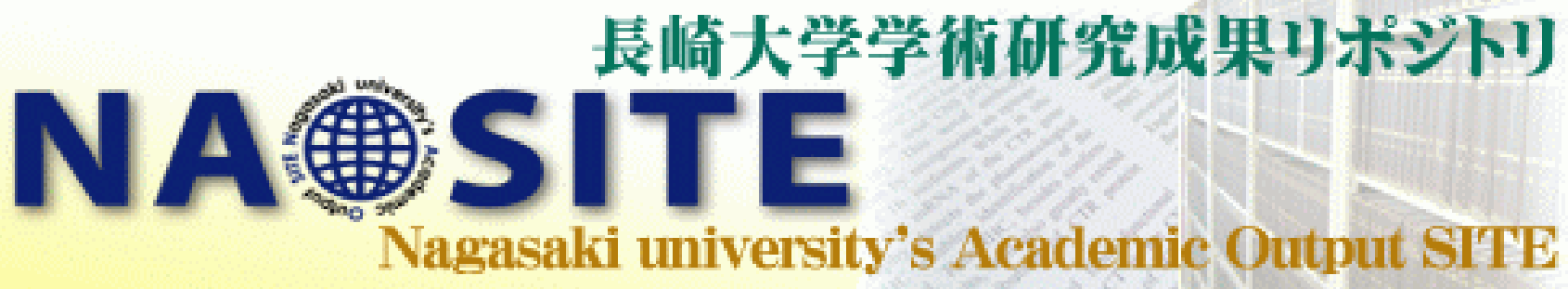

\begin{tabular}{|l|l|}
\hline Title & $\begin{array}{l}\text { Palladium-catalyzed chemoselective anaerobic oxidation of N-heterocycle- } \\
\text { containing al cohols }\end{array}$ \\
\hline Author(s) & $\begin{array}{l}\text { Kuriyama, Masami; Nakashima, Sho; Miyagi, T subasa; Sato, Kanako; } \\
\text { Y amamoto, Kosuke; Onomura, O samu }\end{array}$ \\
\hline Citation & Organic Chemistry Frontiers, 5(15), pp.2364-2369; 2018 \\
\hline Issue Date & $2018-08-07$ \\
\hline URL & http://hdl.handle.net/10069/38545 \\
\hline Right & C 2018 the Partner Organi sations. \\
\hline
\end{tabular}

This document is downloaded at: 2019-08-23T 05:10:40Z 


\title{
Organic Chemistry Frontiers
}

\section{RESEARCH ARTICLE}

\section{Palladium-Catalyzed Chemoselective Anaerobic Oxidation of $\mathbf{N}$ - Heterocycle-Containing Alcohols $\uparrow$}

Received 00th January 20xx, Accepted 00th January 20xx

DOI: $10.1039 / \times 0 \times x 00000 x$

www.rsc.org/

\section{Masami Kuriyama,* Sho Nakashima, Tsubasa Miyagi, Kanako Sato, Kosuke Yamamoto and Osamu Onomura*}

\begin{abstract}
The palladium-catalyzed anaerobic oxidation for $N$-heterocycle-containing alcohols has been developed with chloroarenes as oxidants. In this process, primary and secondary alcohols were selectively oxidized even in the presence of cyclic amines as well as heteroarenes, and primary, secondary, and tertiary amino groups were found to be well tolerated. Moreover, a gram-scale chemoselective oxidation was achieved in addition to a double oxidation of a diamino diol.
\end{abstract}

\section{Introduction}

Heterocycles are known as ubiquitous and important structures in bioactive agents, ${ }^{1}$ and metal-catalyzed transformations for heterocycle-containing molecules have been energetically pursued. ${ }^{2}$ This type of process has developmental challenges because high selectivity for a desired functional group to suppress side reactions is required in addition to sufficient catalytic performance to overcome detrimental effects from heterocycles. ${ }^{3,4}$ The oxidation of alcohols into carbonyl products is one of the most fundamental transformations, and a variety of selective oxidation methods for alcohols have been developed. ${ }^{5}$ However, selective oxidation for $\mathrm{N}$-heterocyclecontaining alcohols still remains immensely challenging, particularly in the presence of unprotected cyclic amino groups, ${ }^{6}$ which often leads to poor yields in synthetic studies. ${ }^{7}$ In 2014, a chemoselective aerobic oxidation for amino alcohols with an $\mathrm{N}$-oxyl/copper catalyst was reported by Iwabuchi. ${ }^{8,9}$ While the efficient transformation with no protection for amino moieties was achieved, this process was ineffective for a basic class of structure such as 1,2-amino alcohols. This kind of oxidation method with molecular oxygen as an oxidant is highly attracttive in the light of synthetic utility. ${ }^{10,11}$ Unfortunately, careful safety analysis is necessary for conduct of this route, especially in large scale reactions, because mixtures of organic solvents and molecular oxygen can constitute flammability hazards. ${ }^{9 d, 12}$ On the other hand, no general procedure for chemoselective anaerobic oxidation of $\mathrm{N}$-heterocycle-containing alcohols has been reported. Aryl halides have been utilized as interesting oxidants with transition metal catalysts, which are converted to inert aromatic solvents through reductive dehalogenation. ${ }^{13}$

Graduate School of Biomedical Sciences, Nagasaki University

1-14 Bunkyo-machi, Nagasaki 852-8521, Japan.

E-mail:mkuriyam@nagasaki-u.ac.jp,onomura@nagasaki-u.ac.jp

† Electronic Supplementary Information (ESI) available: Experimental details, spectral data, and charts of ${ }^{1} \mathrm{H}$ and ${ }^{13} \mathrm{C}$ NMR spectra. See DOI: 10.1039/x0xx00000x
In particular, chloroarenes are superior because of their advantages, such as lower cost, easy availability, and high stability. ${ }^{14,15}$ Although this type of oxidation method for alcohols with aryl chlorides has been developed, ${ }^{16}$ its selectivity and tolerance in the presence of $\mathrm{N}$-heterocycles has been scarcely addressed. ${ }^{17}$ Herein, we report a palladium-catalyzed chemoselective anaerobic oxidation of $\mathrm{N}$-heterocycle-containing alcohols with chloroarenes as oxidants.

\section{Results and discussion}

At the beginning, reaction conditions of alcohol oxidation were optimized in the presence of a palladium catalyst (1 mol\%) with phenyl(pyridin-3-yl)methanol (1a) as a model substrate (Table 1). The examination of C1 (Figure 1) was conducted due to its high efficiency for this kind of oxidation process, ${ }^{16 e}$ but the chemical yield remained at the $30 \%$ level (entry 1 ). Then, Ether-imidazolium chlorides L1-3 were screened as ligand precursors, because we recently found that these $N$-heterocyclic carbene (NHC) precursors gave positive effects in the presence of heterocyclic substrates. ${ }^{18}$ The NHC ligand precursor with a phenoxy moiety (L2) proved to be superior to that with a methoxy or isopropoxy group, and a methoxy moiety at the para-position led to a poorer result (entries 2-5). Although the catalyst in situ formed from $\mathbf{P d}$ and $\mathbf{L} 2$ in a 1:1 molar ratio was less effective (entries 3 and 6), the 1:1 molar ratio complex of $\mathrm{Pd} / \mathbf{L 2}$ (C2) provided a comparable yield to that in entry 3

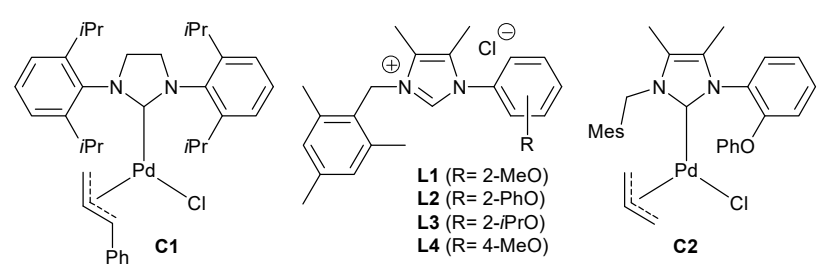

Figure $1 \mathrm{NHC}$ precursors and NHC-Pd complexes. 
Table 1 Optimization of reaction conditions. ${ }^{a}$

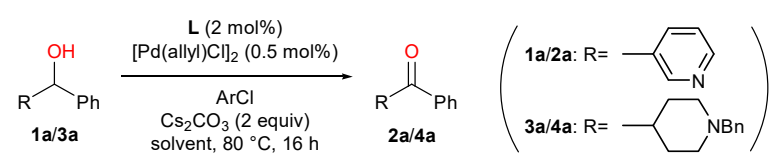

\begin{tabular}{|c|c|c|c|c|c|}
\hline entry & $1 / 3$ & $\mathrm{~L} / \mathrm{C}$ & $\mathrm{ArCl}$ (equiv) & Sovent & Yield (\%) \\
\hline 1 & $1 a$ & $\mathbf{C 1}^{b}$ & $\mathrm{C}_{6} \mathrm{H}_{5} \mathrm{Cl}(1.5)$ & Dioxane & 31 \\
\hline 2 & $1 a$ & L1 & $\mathrm{C}_{6} \mathrm{H}_{5} \mathrm{Cl}(1.5)$ & Dioxane & 67 \\
\hline 3 & $1 a$ & L2 & $\mathrm{C}_{6} \mathrm{H}_{5} \mathrm{Cl}(1.5)$ & Dioxane & 71 \\
\hline 4 & $1 a$ & L3 & $\mathrm{C}_{6} \mathrm{H}_{5} \mathrm{Cl}$ (1.5) & Dioxane & 40 \\
\hline 5 & $1 a$ & L4 & $\mathrm{C}_{6} \mathrm{H}_{5} \mathrm{Cl}(1.5)$ & Dioxane & 26 \\
\hline 6 & $1 a$ & $\mathbf{L 2}^{c}$ & $\mathrm{C}_{6} \mathrm{H}_{5} \mathrm{Cl}(1.5)$ & Dioxane & 61 \\
\hline 7 & $1 \mathrm{a}$ & $\mathbf{C} 2^{b}$ & $\mathrm{C}_{6} \mathrm{H}_{5} \mathrm{Cl}$ (1.5) & Dioxane & 69 \\
\hline 8 & 1a & $\mathbf{L} 2$ & $\mathrm{C}_{6} \mathrm{H}_{5} \mathrm{Cl}(1.5)$ & Toluene & 90 \\
\hline 9 & $1 \mathrm{a}$ & L2 & $\mathrm{C}_{6} \mathrm{H}_{5} \mathrm{Cl}(1.5)$ & DMF & 7 \\
\hline 10 & $1 a$ & L2 & 4- $\mathrm{MeC}_{6} \mathrm{H}_{4} \mathrm{Cl}$ (1.5) & Toluene & 82 \\
\hline 11 & $1 a$ & L2 & 3- $\mathrm{MeC}_{6} \mathrm{H}_{4} \mathrm{Cl}$ (1.5) & Toluene & 84 \\
\hline 12 & $1 a$ & L2 & 2- $\mathrm{MeC}_{6} \mathrm{H}_{4} \mathrm{Cl}$ (1.5) & Toluene & 94 \\
\hline $13^{d}$ & $1 a$ & L2 & 2- $\mathrm{MeC}_{6} \mathrm{H}_{4} \mathrm{Cl}$ (1.2) & Toluene & 77 \\
\hline $14^{d, f}$ & $1 a$ & L2 & 2- $\mathrm{MeC}_{6} \mathrm{H}_{4} \mathrm{Cl}$ (1.2) & Toluene & 99 \\
\hline $15^{d, f}$ & $3 a$ & L2 & 2- $\mathrm{MeC}_{6} \mathrm{H}_{4} \mathrm{Cl}(1.2)$ & Toluene & 73 \\
\hline $16^{d, g}$ & $3 a$ & L2 & 2- $\mathrm{MeC}_{6} \mathrm{H}_{4} \mathrm{Cl}$ (1.2) & Toluene & 82 \\
\hline $17^{e, f}$ & $3 a$ & $\mathrm{~L} 2$ & 2- $\mathrm{MeC}_{6} \mathrm{H}_{4} \mathrm{Cl}$ (1.2) & Toluene & 91 \\
\hline $18^{e, f}$ & $3 a$ & none & 2- $\mathrm{MeC}_{6} \mathrm{H}_{4} \mathrm{Cl}$ (1.2) & Toluene & 0 \\
\hline
\end{tabular}

${ }^{a}$ Reaction conditions: alcohol 1a/3a $(1.0 \mathrm{mmol}), \mathbf{L}(2.0 \mathrm{~mol} \%),\left[\mathrm{Pd}(\text { allyl) } \mathrm{Cl}]_{2}\right.$ (0.5 mol\%), $\mathrm{ArCl}$ (1.2-1.5 equiv), $\mathrm{Cs}_{2} \mathrm{CO}_{3}$ (2.0 equiv), solvent $(2 \mathrm{~mL}), 80^{\circ} \mathrm{C}, 16$ h. ${ }^{b} \mathbf{C}(1.0 \mathrm{~mol} \%)$ was used instead of $\mathbf{L}$ and $[\mathrm{Pd}(\text { allyl }) \mathrm{Cl}]_{2} .{ }^{c} \mathrm{Pd} / \mathbf{L 2}=1 / 1$. ${ }^{d}$ $\mathrm{Cs}_{2} \mathrm{CO}_{3}$ (1.0 equiv). ${ }^{e} \mathrm{CS}_{2} \mathrm{CO}_{3}$ (1.5 equiv). ${ }^{f} 90{ }^{\circ} \mathrm{C} .{ }^{g} 100{ }^{\circ} \mathrm{C}$.

(entry 7). These results suggested that one NHC for Pd would be necessary for the formation of an effective catalyst, and the second one might contribute to the improvement of precatalyst stability. A less polar solvent had a tendency to afford a better yield, and toluene was more suitable (entries 3 and 8-9). Aryl chlorides with a methyl group were tested, and the use of 2-chlorotoluene led to an enhanced result (entries 8 and 1012). A higher reaction temperature gave $99 \%$ yield even with decreasing the amount of 2-chlorotoluene and cesium carbonate (entries 12-14). Subsequently, the catalytic oxidation of a piperidine-containing alcohol 3a was investigated. A higher reaction temperature and amount of cesium carbonate resulted in $82 \%$ and $91 \%$ yields, respectively (entries $15-17$ ). The oxidation with no ligand never proceeded (entry 18).

Investigation of heteroarene-containing secondary alcohols in the palladium-catalyzed oxidation was conducted on the basis of optimized conditions (Scheme 1). Pyridylmethanol derivatives with an electron-donating group on a phenyl moiety showed high reactivity $(\mathbf{2} \mathbf{b}-\mathbf{c})$, and also electron-withdrawing groups gave no serious influence on reaction efficiency (2d-e). As well as a trimethylsilyl group, alkene and alkyne moieties were tolerated in the reaction conditions (2f-h). In the presence of steric hindrance close to a reactive site, the desired products were successfully obtained with the modified conditions (2i-k). The catalytic oxidation of $\alpha$-alkylated pyridylmethanols, such as cyclohexyl(pyridin-3-yl)methanol and 1-(pyridin-
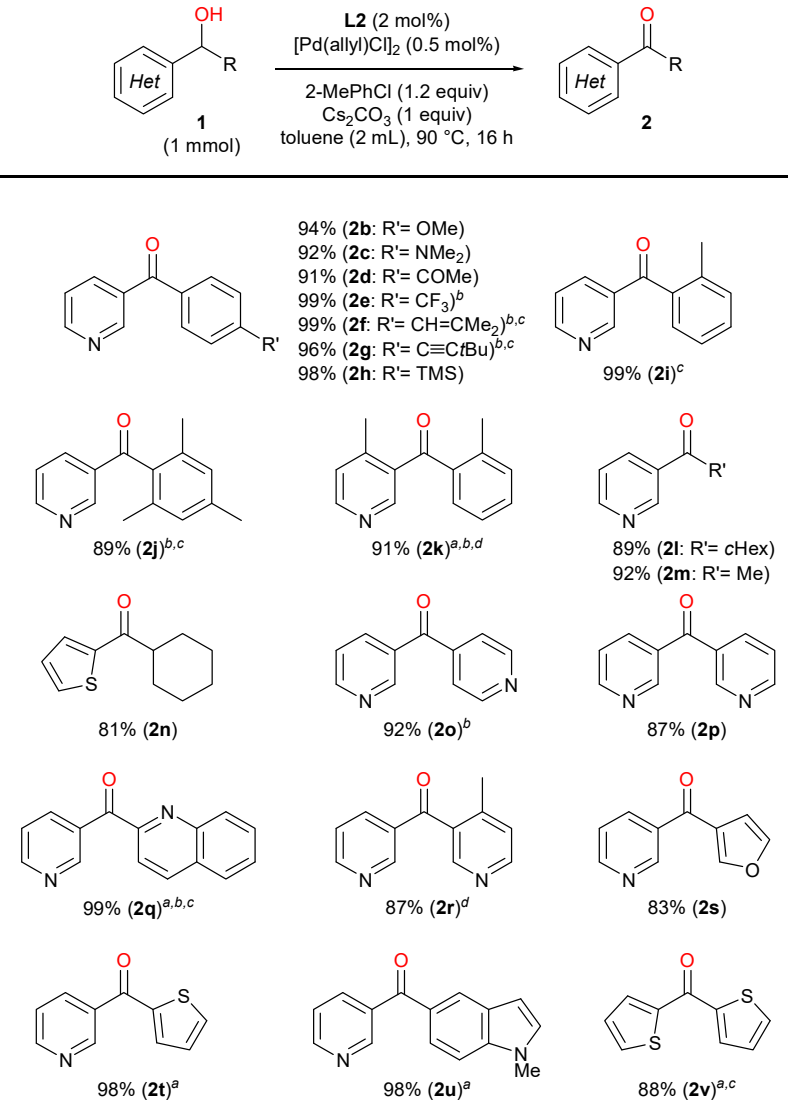<smiles>Cc1ccncc1C(=O)c1cccnc1</smiles><smiles>O=C(c1cccnc1)c1ccoc1</smiles><smiles>O=C(c1cccnc1)c1ccc2c(ccn2[Na])c1</smiles>

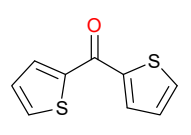

$88 \%(2 \mathbf{v})^{a, c}$

Scheme 1 Oxidation of heteroarene-containing secondary alcohols. ${ }^{a} \mathrm{Pd} / \mathrm{L} 2$ cat. (3 mol\%). ${ }^{b} \mathrm{Cs}_{2} \mathrm{CO}_{3}$ (1.5 equiv). ${ }^{c} 100{ }^{\circ} \mathrm{C} .{ }^{d} 110^{\circ} \mathrm{C}$.

3-yl)ethanol, proceeded efficiently (2I-m), and a thienyl alkanol was additionally found to be a comparably suitable substrate (2n). Subsequently, a series of diheteroarylmethanols were examined in this oxidation reaction. The use of pyridylmethanol derivatives bearing another pyridyl or quinolyl group led to high yields (2o-q), and an ortho-substituted substrate was also smoothly oxidized at a higher temperature (2r). This oxidation process sufficiently tolerated electron-rich heteroaryl groups, such as furan, thiophene, and indole (2s-u). In the case of a dithienylmethanol, no significant decrease in yield was observed, providing desired product $\mathbf{2 v}$ in $88 \%$ yield.

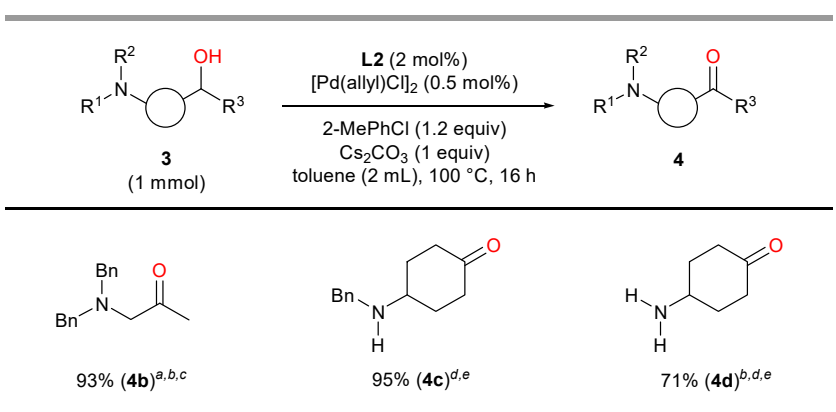

Scheme 2 Oxidation of amino alcohols. ${ }^{a} \mathrm{Pd} / \mathrm{L2}$ cat. (3.0 mol\%). ${ }^{b} \mathrm{Cs}_{2} \mathrm{CO}_{3}$ (1.5 equiv). ${ }^{c} 110{ }^{\circ} \mathrm{C} .{ }^{d} 2,6-\mathrm{Me}_{2}-\mathrm{PhCl}$ (1.2 equiv). ${ }^{e}$ The product was isolated as a $\mathrm{Cbz}-$ protected form. 

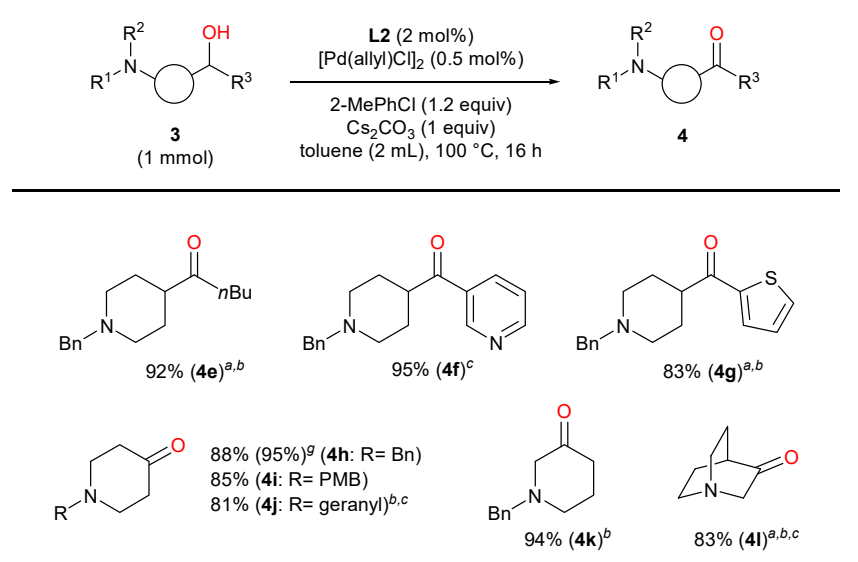

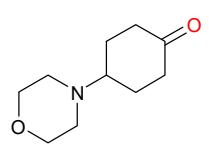

$88 \%(4 \mathrm{~m})$
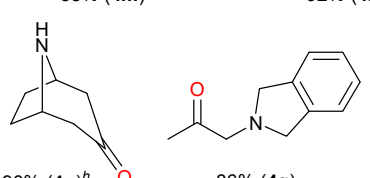

$86 \%(4 q)$

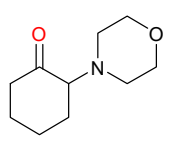

$91 \%(\mathbf{4 t})^{d}$

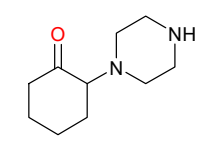

$81 \%(4 \mathbf{u})^{a, b, d, h}$

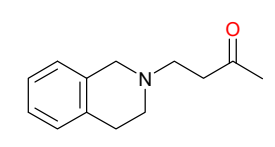

$94 \%(40)^{a, b, e}$

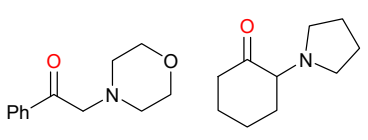

$90 \%(4 \mathbf{r})^{a}$

$81 \%(\mathbf{4 s})^{a}$

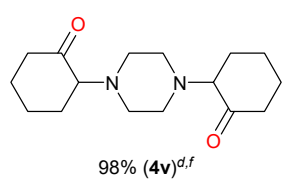

Scheme 3 Oxidation of cyclic amine-containing secondary alcohols. ${ }^{a} \mathrm{Pd} / \mathbf{L 2}$ cat (3.0 mol\%). ${ }^{b} \mathrm{Cs}_{2} \mathrm{CO}_{3}$ (1.5 equiv). ${ }^{c} 90{ }^{\circ} \mathrm{C} .{ }^{d} 110{ }^{\circ} \mathrm{C} .{ }^{e} 2,6-\mathrm{Me}_{2}-\mathrm{PhCl}$ (1.2 equiv). $f \mathrm{Pd} / \mathrm{L} 2$ cat. (6.0 mol\%), 2,6- $\mathrm{Me}_{2}-\mathrm{PhCl}$ (2.4 equiv), $\mathrm{Cs}_{2} \mathrm{CO}_{3}$ (3.0 equiv). ${ }^{g} \mathrm{Gram}$-scale reaction (3h: $8.0 \mathrm{mmol}) .{ }^{h}$ The product was isolated as a Cbz-protected form.

To examine the influence of amino groups, the catalytic oxidation of a few challenging amino alcohols ${ }^{8}$ was carried out (Scheme 2). A vicinal amino alcohol containing a tertiary amino moiety was successfully oxidized into the corresponding amino ketone (4b). In addition to a secondary amino group, a primary amino moiety proved to be well tolerated in this alcohol oxidation (4c-d). ${ }^{19}$ These results encouraged us to explore cyclic amine-containing secondary alcohols (Scheme 3). Piperidinemethanol derivatives bearing a heteroaromatic ring as well as an alkyl group at the $\alpha$-position adequately reacted to provide high yields (4e-g). In the synthesis of piperidones, a gram-scale oxidation process was achieved with high efficiency (4h), and relatively easily oxidized $N$-substituents such as benzyl, $p$ methoxybenzyl, and geranyl groups were applicable without problems (4i-k). Quinuclidine, morpholine, and phenothiazine frameworks did not give a significant decrease in yield (4I-n), and a 1,3-amino alcohol with a tetrahydroisoquinoline was also converted effecttively (4o). The selective oxidation of nortropine smoothly proceeded even in the presence of a secondary amino group (4p). Then, 1,2-amino alcohols containing a heterocycle such as isoindoline and morpholine were tried out to deliver notable results $(\mathbf{4 q - r})$. In the case of cyclic 1,2-amino alcohols, ${ }^{19}$ an unprotected piperazyl group was
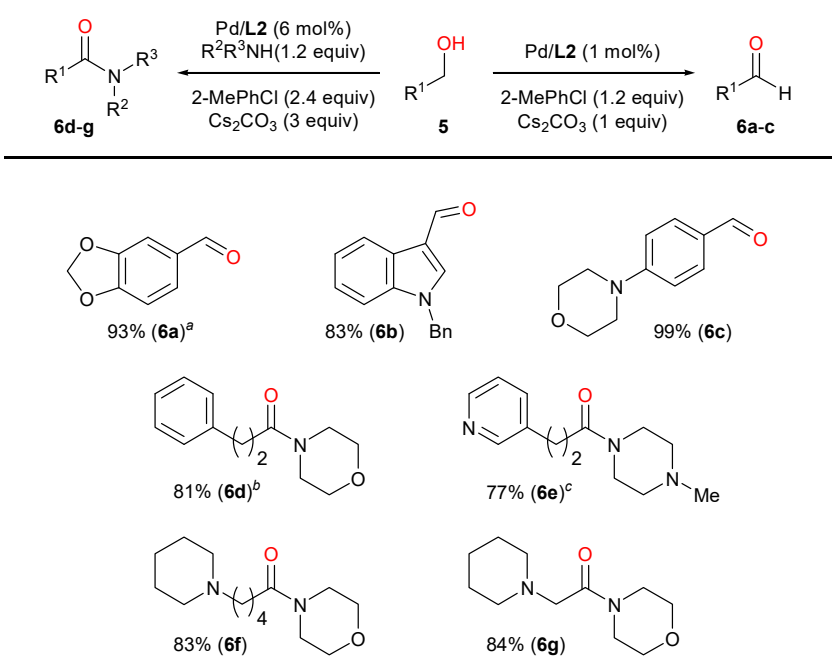

Scheme 4 Oxidation of primary alcohols. Conditions (aldehyde synthesis): 5 (1.0 mmol), $\left[\mathrm{Pd}(\text { allyl)Cl}]_{2}\right.$ (0.5 mol\%), L2 (2.0 mol\%), 2-MePhCl (1.2 equiv), $\mathrm{Cs}_{2} \mathrm{CO}_{3}$ (1.0 equiv), toluene $(2.0 \mathrm{~mL}), 90{ }^{\circ} \mathrm{C}, 16 \mathrm{~h}$. Conditions (amide synthesis): $5(1.0 \mathrm{mmol})$, $\left[\mathrm{Pd}(\text { allyl)Cl}]_{2}\right.$ (3.0 mol\%), L2 (12 mol\%), amine (1.2 equiv), 2-MePhCl (2.4 equiv), $\mathrm{Cs}_{2} \mathrm{CO}_{3}$ (3.0 equiv), toluene $(2.0 \mathrm{~mL}), 100{ }^{\circ} \mathrm{C}, 16 \mathrm{~h}$. ${ }^{a} 9$-Cl-anthracene (1.2 equiv). ${ }^{b}$ $\mathrm{Pd} / \mathrm{L2}$ cat. (3 mol\%), 2,6-Me $-\mathrm{PhCl}\left(2.4\right.$ equiv). ${ }^{c} 110^{\circ} \mathrm{C}$.

found to be acceptable as well as pyrrolidine and morpholine

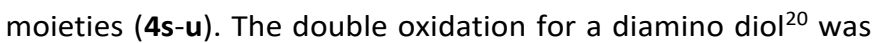
also successfully conducted, leading to $98 \%$ yield (4v).

The palladium-catalyzed oxidation of primary alcohols was investigated (Scheme 4). Early in the study, ester formation was observed in the catalytic oxidation of 3-phenylpropyl alcohol (5d), while piperonyl alcohol proved to be a good substrate (6a). Therefore, the oxidative conversion of $\mathbf{5} \mathbf{d}$ was carried out in the presence of morpholine, and the expected amide product was successfully obtained through selective oxidation of the alcohol and hemiaminal (6d). Benzylic alcohols with a heteroarene or cyclic amine moiety were readily converted into the corresponding aldehydes in high yields $(\mathbf{6 b}-\mathbf{c})$. The catalytic coupling of 3-pyridinepropanol with 1-methylpiperazine led to

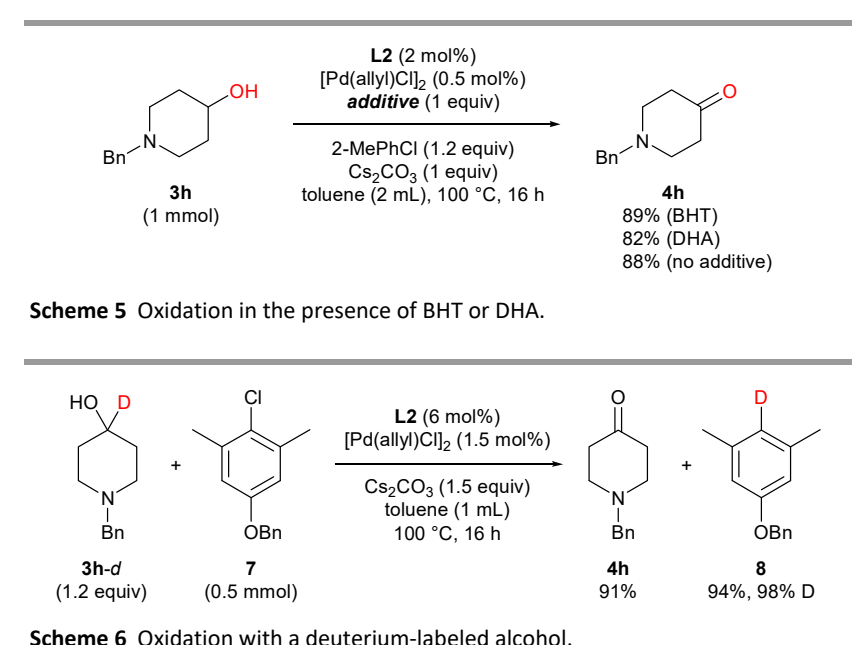




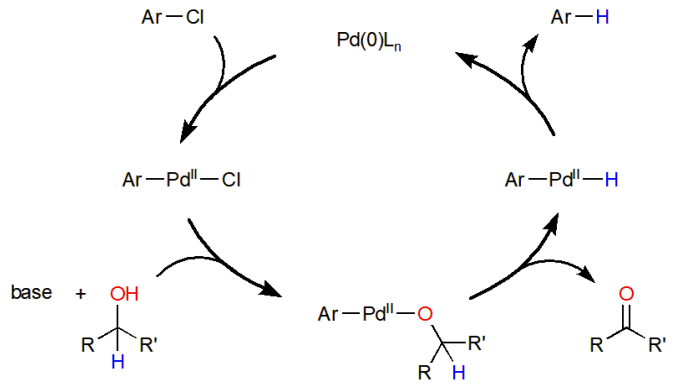

Scheme 7 Plausible reaction mechanism.

a desired amide formation with sufficient efficiency (6e). A vicinal amino alcohol with a piperidyl group was also found to be suitable as well as 1-piperidinepentanol (6f-g).

The palladium-catalyzed oxidation of amino alcohol $\mathbf{3 h}$ smoothly proceeded even in the presence of a radical scavenger, such as 2,6-di-tert-butyl-4-methylphenol (BHT) and 9,10dihydroanthracene (DHA) (Scheme 5). These results suggested that a single electron transfer process might not be involved in the reaction mechanism of this catalytic oxidation method.

Subsequently, the selective oxidation of deuterium-labeled alcohol $\mathbf{3 h}-\boldsymbol{d}$ was examined with aryl chloride $\mathbf{7}$ as an oxidant, giving amino ketone $\mathbf{4 h}$ and deuterated arene $\mathbf{8}$ in high yields (Scheme 6). ${ }^{21}$ This experimental outcome revealed that the $\alpha$ hydrogen atom of an alcohol was transferred to an arene molecule through the $\mathrm{C}-\mathrm{Cl}$ bond cleavage in an aryl chloride.

On the basis of these observations, a plausible reaction mechanism for this catalytic oxidation of alcohols is presented in Scheme 7. In the first step, an aryl-palladium intermediate is formed through the oxidative addition of an aryl chloride to a $\mathrm{Pd}(0)$ complex. After the displacement of a chloride anion is promoted by a base, an alkoxy-palladium species undergoes $\beta$ hydrogen elimination to afford an aryl-palladium-hydride complex with the formation of a carbonyl product. Then, reductive elimination provides an arene, and a $\operatorname{Pd}(0)$ catalyst is regenerated. This reaction mechanism is consistent with findings in previous reports. ${ }^{16}$

\section{Conclusions}

In summary, a chemoselective anaerobic oxidation for $\mathrm{N}$-heterocycle-containing alcohols was achieved with aryl chlorides as oxidants in the presence of a NHC-ligated palladium catalyst. This catalytic process proceeded with sufficient efficiency, and a variety of primary and secondary alcohols were effectively converted into carbonyl products in high yields. As well as heteroarenes, cyclic amines were well tolerated in this system, and primary, secondary, and tertiary amino groups proved to be suitable. Furthermore, a gram-scale oxidation reaction was successfully carried out in addition to a double oxidation of a vicinal amino alcohol. We believe that this oxidation method would contribute to the progress of selective transformations required in the synthesis of biologically active molecules.

\section{Experimental}

General procedure for the palladium-catalyzed chemoselective anaerobic oxidation of $\boldsymbol{N}$-heterocycle-containing alcohols

Under an argon atmosphere, a reaction tube was charged with ligand precursor $\mathbf{L} 2(8.66 \mathrm{mg}, 0.02 \mathrm{mmol}),\left[\mathrm{Pd}(\right.$ allyl $) \mathrm{Cl}_{2}(1.83$ $\mathrm{mg}, 0.005 \mathrm{mmol}$ ), and $\mathrm{Cs}_{2} \mathrm{CO}_{3}(326 \mathrm{mg}, 1.0 \mathrm{mmol})$. After dry toluene $(2.0 \mathrm{~mL})$ was added, this mixture was stirred at $80^{\circ} \mathrm{C}$ for $15 \mathrm{~min}$. Subsequently, a $\mathrm{N}$-heterocycle-containing alcohol (1.0 mmol) and 2-chlorotoluene $(152 \mathrm{mg}, 1.2 \mathrm{mmol}$ ) were added at room temperature, and the reaction mixture was stirred at $90{ }^{\circ} \mathrm{C}$ for $16 \mathrm{~h}$. After water was added at room temperature, the resulting mixture was extracted with AcOEt. The combined organic layers were dried over $\mathrm{Na}_{2} \mathrm{SO}_{4}$. Concentration and purification through silica gel column chromatography gave a desired product.

\section{Conflicts of interest}

There are no conflicts of interest to declare.

\section{Acknowledgements}

This research was supported by JSPS KAKENHI (15K07862 and 16K08167) and Research Grant for Pharmaceutical Sciences from Takeda Science Foundation.

\section{Notes and references}

1 For reviews, see: (a) R. M. Wilson and S. J. Danishefsky, Chem. Soc. Rev., 2007, 36, 1207-1226; (b) J. Yamaguchi, A. D. Yamaguchi and K. Itami, Angew. Chem. Int. Ed., 2012, 51, 89609009; (c) A. M. Armaly, Y. C. DePorre, E. J. Groso, P. S. Riehl and C. S. Schindler, Chem. Rev., 2015, 115, 9232-9276; (d) C. Cabrele and O. Reiser, J. Org. Chem., 2016, 81, 10109-10125.

2 For recent examples, see: (a) C. M. Filloux and T. Rovis, J. Am. Chem. Soc., 2015, 137, 508-517; (b) P. W. Tan, M. Haughey and D. J. Dixon, Chem. Commun., 2015, 51, 4406-4409; (c) V. R. Bhonde, B. T. O'Neill and S. L. Buchwald, Angew. Chem. Int Ed., 2016, 55, 1849-1853; (d) T. Gensch, F. J. R. Klauck and F. Glorius, Angew. Chem. Int. Ed., 2016, 55, 11287-11291; (e) P. Schäfer, T. Palacin, M. Sidera and S. P. Fletcher, Nat. Commun., 2017, 8, 15762-15769; (f) W. C. Fu, Z. Wang, W. T. K. Chan, Z. Lin and F. Y. Kwong, Angew. Chem. Int. Ed., 2017, 56, 7166-7170; (g) L. Bering, F. M. Paulussen and A. P. Antonchick, Org. Lett., 2018, 20, 1978-1981.

3 For reviews, see: (a) N. A. Afagh and A. K. Yudin, Angew. Chem. Int. Ed., 2010, 49, 262-310; (b) Y. Seki, K. Oisaki and M. Kanai, Tetrahedron Lett., 2014, 55, 3738-3746.

4 (a) D. Zhao, J. You and C. Hu, Chem. Eur. J., 2011, 17, 54665492; (b) S. Ge and J. F. Hartwig, Angew. Chem. Int. Ed., 2012, 51, 12837-12841.

5 For reviews, see: (a) R. A. Sheldon and J. K. Kochi, MetalCatalyzed Oxidations of Organic Compounds; Academic Press: New York, 1981; (b) M. Hudlicky, Oxidations in Organic Chemistry, ACS Monograph Series; American Chemical Society: Washington, DC, 1990; (c) J.-E. Bäckvall, Modern Oxidation Methods, 2nd ed.; Wiley-VCH: Weinheim, 2010. For recent examples of selective oxidation, see: (d) L. Han, P. Xing and B. Jiang, Org. Lett., 2014, 16, 3428-3431; (e) X. Chen, Y. Zhang, H. Wan and S. Zhang, Chem. Commun., 2016, 52, 3532-3535; (f) A. Vasseur, R. Membrat, D. Gatineau, A. 
Tenaglia, D. Nuel and L. Giordano, ChemCatChem, 2017, 9, 728-732.

6 Protection of amino groups as amides or carbamates is typically conducted before the oxidation of alcohol moieties in amino alcohols, which reduces synthetic efficiency: P. G. M. Wuts and T. W. Greene, Greene's Protective Groups in Organic Synthesis, 5th ed., Wiley, Hoboken, 2014.

7 (a) M. H. Becker, P. Chua, R. Downham, C. J. Douglas, N. K. Garg, S. Hiebert, S. Jaroch, R. T. Matsuoka, J. A. Middleton, F. W. Ng and L. E. Overman, J. Am. Chem. Soc., 2007, 129, 11987-12002; (b) H. Y. Lin, R. Causey, G. E. Garcia and B. B. Snider, J. Org. Chem., 2012, 77, 7143-7156; (c) K. Geoghegan and P. Evans, J. Org. Chem., 2013, 78, 3410-3415.

8 Y. Sasano, S. Nagasawa, M. Yamazaki, M. Shibuya, J. Park and Y. Iwabuchi, Angew. Chem. Int. Ed., 2014, 53, 3236-3240.

9 The direct amide synthesis from alcohols and amines via selective oxidation of alcohols and hemiaminals was reported. For a pioneering work, see: (a) C. Gunanathan, Y. BenDavid and D. Milstein, Science, 2007, 317, 790-792. For recent examples, see: (b) P. Hu, Y. Ben-David and D. Milstein, Angew. Chem. Int. Ed., 2016, 55, 1061-1064; (c) Z. Wu and K. L. Hull, Chem. Sci., 2016, 7, 969-975; (d) S. L. Zultanski, J. Zhao and S. S. Stahl, J. Am. Chem. Soc., 2016, 138, 6416-6419.

10 For examples of Cu catalysts, see: (a) M. F. Semmelhack, C. R. Schmid, D. A. Cortes and C. S. Chou, J. Am. Chem. Soc., 1984, 106, 3374-3376; (b) I. E. Markó, P. R. Giles, M. Tsukazaki, S. M. Brown and C. J. Urch, Science, 1996, 274, 2044-2046; (c) P. Gamez, I. W. C. E. Arends, J. Reedijk and R. A. Sheldon, Chem. Commun., 2003, 39, 2414-2415; (d) E. T. T. Kumpulainen and A. M. P. Koskinen, Chem. Eur. J., 2009, 15, 10901-10911; (e) J. E. Steves and S. S. Stahl, J. Am. Chem. Soc., 2013, 135, 1574215745; (f) D. Könning, T. Olbrisch, F. D. Sypaseuth C. C. Tzschucke and M. Christmann, Chem. Commun., 2014, 50, 5014-5016; (g) B. Xu, J.-P. Lumb and B. A. Arndtsen, Angew. Chem. Int. Ed., 2015, 54, 4208-4211. (h) S. D. McCann, J.-P. Lumb, B. A. Arndtsen and S. S. Stahl, ACS Cent. Sci., 2017, 3 314-321.

11 For examples of Pd catalysts, see: (a) T. Nishimura, T. Onoue, K. Ohe and S. Uemura, J. Org. Chem., 1999, 64, 6750-6755 (b) G.-J. ten Brink, I. W. C. E. Arends and R. A. Sheldon, Science, 2000, 287, 1636-1639; (c) J. A. Mueller, C. P. Goller and M. S. Sigman, J. Am. Chem. Soc., 2004, 126, 9724-9734 (d) B. A. Steinhoff, I. A. Guzei and S. S. Stahl, J. Am. Chem. Soc., 2004, 126, 11268-11278; (e) D. C. Ebner, R. M. Trend, C. Genet, M. J. McGrath, P. O'Brien and B. M. Stoltz, Angew. Chem. Int. Ed., 2008, 47, 6367-6370; (f) D. S. Bailie, G. M. A. Clendenning, L. McNamee and M. J. Muldoon, Chem. Commun., 2010, 46, 7238-7240; (g) N. Armenise, N. Tahiri, N. N. H. M. Eisink, M. Denis, M. Jäqer, J. G. De Vries, M. D. Witte and A. J. Minnaard, Chem. Commun., 2016, 52, 2189-2191.

12 (a) B. A. Steinhoff and S. S. Stahl, J. Am. Chem. Soc., 2006, 128, 4348-4355; (b) P. M. Osterberg, J. K. Niemeier, C. J. Welch, J. M. Hawkins, J. R. Martinelli, T. E. Johnson, T. W. Root and S. S. Stahl, Org. Process Res. Dev., 2015, 19, 15371543; (c) J. E. Steves, Y. Preger, J. R. Martinelli, C. J. Welch, T. W. Root, J. M. Hawkins and S. S. Stahl, Org. Process Res. Dev. 2015, 19, 1548-1553.

13 For an early example of alcohol oxidation with $\mathrm{Pd}$ (II) salts, see: (a) W. G. Lloyd, J. Org. Chem., 1967, 32, 2816-2818; For examples of Pd-catalyzed oxidation of alcohols with organic halides as oxidants, see: (b) Y. Tamaru, Y. Yamada, K. Inoue, Y. Yamamoto and Z. Yoshida, J. Org. Chem., 1983, 48, 12861292; (c) S. Bouquillon, F. Hénin and J. Muzart, Organometallics, 2000, 19, 1434-1437.

14 For a review, see: A. F. Littke and G. C. Fu, Angew. Chem. Int. Ed., 2002, 41, 4176-4211.

15 For recent examples of catalytic reactions with aryl chlorides, see: (a) J. A. Fernández-Salas, E. Marelli and S. P. Nolan,
Chem. Sci., 2015, 6, 4973-4977; (b) W. C. Fu, C. M. So, W. K. Chow, O. Y. Yuen and F. Y. Kwong, Org. Lett., 2015, 17, 46124615; (c) D. Martinez-Solorio, B. Melillo, L. Sanchez, Y. Liang, E. Lam, K. N. Houk and A. B. Smith III, J. Am. Chem. Soc., 2016, 138, 1836-1839; (d) M. Fan, E. Zhou, Y. Jiang and D. Ma, Angew. Chem. Int. Ed., 2016, 55, 6211-6215; (e) M. Yamaguchi, K. Suzuki, Y. Sato and K. Manabe, Org. Lett., 2017, 19, 5388-5391; (f) S. Sharif, J. Day, H. N. Hunter, Y. Lu, D. Mitchell, M. J. Rodriguez and M. G. Organ, J. Am. Chem. Soc., 2017, 139, 18436-18439; (g) K. D. Jones, D. J. Power, D. Bierer, K. M. Gericke and S. G. Stewart, Org. Lett., 2018, 20, 208-211.

16 (a) A. S. Guram, X. Bei and H. W. Turner, Org. Lett., 2003, 5 , 2485-2487; (b) X. Bei, A. Hagemeyer, A. Volpe, R. Saxton, H. Turner and A. S. Guram, J. Org. Chem., 2004, 69, 8626-8633; (c) C. Berini, D. F. Brayton, C. Mocka and O. Navarro, Org. Lett., 2009, 11, 4244-4247; (d) C. Berini, O. H. Winkelmann, J. Otten, D. A. Vicic and O. Navarro, Chem. Eur. J., 2010, 16, 6857-6860; (e) B. Landers, C. Berini, C. Wang and O. Navarro, J. Org. Chem., 2011, 76, 1390-1397.

17 Only one example was reported in ref $16 \mathrm{~b}$.

18 M. Kuriyama, S. Matsuo, M. Shinozawa and O. Onomura, Org. Lett., 2013, 15, 2716-2719.

19 The trans-isomers were used as starting materials (3c-d, $\mathbf{3 m}$, and $3 \mathbf{s}-\mathbf{u}$ ).

20 The mixture of diastereomers was used as starting materials (3v).

21 For the isolation and analysis of $\mathbf{8}$, an excessive amount of $\mathbf{3 h}-d$ was used due to difficulty in the separation of $\mathbf{8}$ from $\mathbf{7}$. 